\title{
Direitos republicanos e a captura "legal" do Estado brasileiro
}

Luiz Carlos Bresser-Pereira

Fundação Getúlio Vargas (FGV)

Direitos republicanos são os direitos que cada cidadão tem de que o patrimônio público seja utilizado para fins públicos. São um quarto tipo de direito de cidadania, depois dos direitos civis, dos direitos políticos e dos direitos sociais. A captura do patrimônio público não se limita à simples corrupção; os direitos republicanos são frequentemente violentados por meios legais. Os privatizadores públicos podem ser rentistas que recebem juros escandalosamente altos do Estado, são altos servidores que não trabalham ou cujos proventos não são proporcionais a seu trabalho, são indivíduos e empresas que se apropriam do meio ambiente ou a ele causam prejuízo. Neste trabalho, eu listo os principais grupos que capturam o patrimônio público ou a res publica no Brasil.

Palavras-chave: patrimônio público - Brasil, corrupção, agenda - pesquisa

[Artigo recebido em 16 de abril de 2018. Aprovado em 19 de setembro de 2018.] 


\section{Derechos republicanos y la captura 'legal' del Estado brasileño}

Los derechos republicanos son los derechos que cada ciudadano tiene de que el patrimonio público sea utilizado para fines públicos. Son un cuarto tipo de derecho de ciudadanía, después de los derechos civiles, de los derechos políticos y de los derechos sociales. La captura del patrimonio público no se limita a la simple corrupción; los derechos republicanos son a menudo violados por medios legales. Los privatizadores públicos pueden ser rentistas que reciben intereses escandalosamente altos del Estado, son altos servidores que no trabajan o cuyos ingresos no son proporcionales a su trabajo, son individuos y empresas que se apropian del medio ambiente o a él causan perjuicio. En este trabajo, yo listo los principales grupos que capturan el patrimonio público o la res publica en Brasil.

Palabras clave: patrimonio público - Brasil, corrupción, agenda - investigación

\section{Republican rights and the 'legal' capture of the Brazilian State}

Republican rights are the rights that every citizen has that the public patrimony is used for public purposes. They are a fourth type of citizenship right, after the civil rights, the political rights and the social rights. The capture of public patrimony is not limited to mere corruption; republican rights are often violated by legal means. Public privatizers may be rentiers who receive scandalously high interest from the state, may be high public officials who do not work or whose salaries and pensions are not commensurate with their work, may be individuals and companies who appropriate or harm the environment. In this article, I will list the main groups that capture the res publica in Brazil.

Keywords: public patrimony - Brazil, corruption, agenda - research 
O Estado é o adversário dos liberais, porque intervém na economia e impede o mercado de realizar sua missão coordenadora, mas é também seu garantidor maior, porque eles sabem que sem o Estado garantir a propriedade e os contratos não há capitalismo; é o adversário dos marxistas clássicos, porque representa os interesses da burguesia, mas para os marxistas modernos e para a esquerda, que aprenderam com Antonio Gramsci e Nicos Poulantzas que o Estado é uma "condensação da luta de classes", ele se tornou um instrumento a ser conquistado, porque, no quadro da democracia, pode proteger os trabalhadores e os pobres. Em qualquer circunstância, além de reproduzir a luta por hegemonia ideológica que ocorre na sociedade civil, além de garantir a ordem capitalista enquanto não houver alternativa para ela, o Estado é o instrumento de ação coletiva da nação na sua luta pelo desenvolvimento, pela redução das desigualdades e pela proteção do ambiente. O Estado quase se confunde com o patrimônio público, porque este é, em primeiro lugar, o Tesouro do Estado e o fluxo de despesas previstas no seu orçamento. E por isso, é o objeto da cobiça e da captura por indivíduos e por grupos de indivíduos poderosos e espertos que tornam efetiva essa captura não apenas através da corrupção, mas também através da violência legal contra os direitos republicanos.

Desenvolvi o conceito de direitos republicanos enquanto Ministro da Administração Federal e Reforma do Estado, em um trabalho, "Cidadania e res publica: a emergência dos direitos republicanos", no qual parti da definição de T.H. Marshall (1950) das três formas históricas de direitos no Reino Unido - os direitos civis, definidos no século 18 , os direitos políticos alcançados no final do século 19 , com a conquista do sufrágio universal, e os direitos sociais. Diante do grande número de referências que eu lia ou ouvia de cientistas sociais, tanto de esquerda quanto de direita, sobre a "captura", a "privatização" do Estado e o rent seeking, concluí que, no final do século 20 , estava surgindo um quarto tipo histórico de direito, que chamei de "direitos republicanos". Eles se referem ao direito que todo cidadão tem de que o patrimônio público seja utilizado para fins públicos. Eles se originam não apenas da corrupção, mas de omissões legais que permitem que indivíduos e grupos possam capturar o patrimônio público sem ir contra a lei. Em livro posterior, Construindo o Estado Republicano (2004), eu denominei o Estado que é capaz de proteger os direitos republicanos e, portanto, de se defender das permanentes tentativas de captura privada de "Estado republicano".

Para os políticos, o objetivo é alcançar o poder do Estado; é obter o poder de legislar e tributar, ou, nos termos de Max Weber, de exercer o monopólio da violência legítima. Com que objetivo? Para os republicanos, para defender o interesse público ou o bem comum; para os liberais, para preservar a liberdade individual e o capitalismo; para os desenvolvimentistas, para acelerar o crescimento 
no quadro do capitalismo; para os socialistas, para acabar com as desigualdades através da transição para o socialismo; para os progressistas, também para diminuir as desigualdades, mas no quadro provisório e limitado do capitalismo; e para os ambientalistas, para defender o ambiente e limitar o aquecimento global. A cada um desses objetivos corresponde uma ideologia: o republicanismo, o liberalismo, o desenvolvimentismo, o socialismo e o ambientalismo. Essas ideologias expressam valores maiores, mas são também utilizadas de maneira perversa por intelectuais orgânicos que desenvolvem discursos aparentemente racionais e justos, mas que na verdade refletem seus interesses e preconceitos e os da classe dominante que representam. Ao contrário do liberalismo, que defende apenas os direitos civis, o republicanismo (a ideologia pertinente ao conceito de direitos republicanos) defende o civismo, as obrigações de cada cidadão para com sua sociedade e seu Estado. Enquanto o liberalismo define liberdade como o direito do cidadão de fazer o que bem lhe aprouver, o republicanismo a define como a capacidade de cada cidadão de agir em defesa do interesse público, mesmo que essa ação prejudique seus interesses particulares. O republicanismo é a ideologia própria dos servidores públicos, é a ideologia do civismo ou do etos público.

Nas sociedades democráticas modernas, nas quais o uso direto da força perdeu relativo poder porque os cidadãos não se submetem a ela, as ideologias tornaramse especialmente importantes. As classes dominantes estão a par disso, e usam uma infinidade de estratégias para alcançar esse objetivo: o controle ideológico da mídia, da universidade, das editoras mais importantes. E "compram", através dos mais variados meios, os políticos que vão governar, e os intelectuais - hoje principalmente economistas neoclássicos - que, assim, dão caráter "científico" à ideologia dominante. Nessa linha de pensamento, na segunda metade do século 20 é impressionante ver como a universidade foi colocada a serviço do liberalismo através das ideias da Escola da Escolha Pública. Esses intelectuais se dispuseram a "abrir a caixa negra do Estado", ou seja, ao invés de supor que o governo está a serviço do interesse geral, como supõe o liberalismo comum, buscou entender a lógica da ação dos políticos. O político seria aquele que faz compensações entre a vontade de ser eleito e a busca de vantagens pessoais através do controle do Estado (rent seeking). Dessa forma, esses liberais desmoralizavam o político, os governos, e justificavam a retirada do Estado da vida econômica. Mas, ainda que a realidade do capitalismo não seja muito melhor do que isso, ela é suficientemente melhor para que os republicanos possam afirmar que há dois tipos de político e não apenas um: há o político vulgar, que age de acordo com o pressuposto da Escolha Pública, e há o político republicano, que faz trade-offs entre a vontade de ser eleito e o interesse público. Nenhuma sociedade terá uma maioria de políticos e cidadãos republicanos, mas quanto maior for a sua proporção na população do país, mais 
avançado será esse país, e menor será a possibilidade de captura do patrimônio público por interesses privados.

Faço essas afirmações gerais pensando no Estado moderno em geral, mas elas se aplicam ao Estado brasileiro. Neste breve artigo, que deve ser compreendido como uma agenda de pesquisa, vou usá-las para discutir não o Estado brasileiro em geral, mas para responder a uma questão: quem captura o Estado no Brasil, quem o utiliza para atender a seus próprios objetivos e não para servir os interesses gerais? Quem, em outras palavras, e além dos meramente corruptos, desrespeita os direitos republicanos dos brasileiros, e por que meios?

Sabemos que o Estado afeta de maneira poderosa a repartição da renda em um país pela ação e pela omissão. Afeta-a de maneira saudável, quando é um instrumento de diminuição das desigualdades; de maneira perversa, quando as aprofunda. O Estado brasileiro, historicamente, afetou de forma perversa a distribuição. Entretanto, com a adoção de uma estratégia desenvolvimentista, realizou a revolução capitalista a partir de 1930, que favoreceu a emergência da democracia, em 1985. A partir desse momento, o Estado brasileiro, atendendo à demanda de uma sociedade fortalecida pelo sufrágio universal, procurou se constituir em um Estado social, mas, ao mesmo tempo, a economia brasileira deixou de crescer, vítima dos erros dos governos liberais e dos governos de esquerda dos últimos 33 anos. Em consequência, o Estado brasileiro encontra-se hoje em profunda crise. Na próxima seção vou ver, muito resumidamente, a evolução histórica desse Estado, para, na seção final, ver como ele é objeto de captura por indivíduos ou grupos poderosos.

\section{História resumida}

Nos países que primeiro realizaram sua revolução capitalista, o Estado moderno (1) nasceu absoluto e patrimonialista; (2) transformou-se no século 19 em um Estado liberal e racional-legal, ocorrendo então a separação entre o patrimônio público e o patrimônio privado, e os direitos civis passaram a ser assegurados; (3) tornouse em Estado liberal-democrático na virada para o século 20, quando os direitos políticos ou a democracia passaram a ser garantidos; (4) transformou-se em Estado democrático social e desenvolvimentista no após Segunda Guerra Mundial, quando principalmente os países europeus tornaram-se desenvolvimentistas, adotaram sistemas tributários progressivos e ampliaram suas despesas na área social, dando origem ao Estado do Bem-estar Social; mas, entre aproximadamente 1980 e 2008, (5) o Estado que se tornara social-democrático regrediu para uma condição liberaldemocrática na medida em que as elites econômicas - agora financeiro-rentistas - 
se engajaram em reformas destinadas a eliminar os direitos trabalhistas e reduzir os grandes serviços sociais do Estado social, enquanto a ideologia dominante passava a ser o neoliberalismo caracterizado por um individualismo radical.

Essa transição de uma forma progressiva para uma forma reacionária do Estado foi consequência de três fatos históricos novos: o aumento do poder dos sindicatos desde os anos 1960; uma crise econômica nos anos 1970 definida pela queda da taxa de lucro, principalmente nos Estados Unidos; e a concorrência dos países em desenvolvimento que, nos anos 1970, passaram a ser exportadores de manufaturados beneficiando-se de sua mão de obra barata. Para fazer frente a esses problemas, a nova ordem neoliberal passou a adotar, desde os anos 1980, reformas radicais, uma verdadeira contrarrevolução financeiro-rentista. Mas elas nunca se completam nem podem se completar porque a complexidade das relações econômicas e o fato de que o mercado não consegue dar conta delas criam a necessidade permanente de se regular o capitalismo. Os neoliberais, porém, dominados por um "fundamentalismo de mercado", quando ocupam o governo passam a realizar "reformas", que segundo eles produzem o aumento de competitividade, mas, na maioria dos casos, resultam em diminuição das taxas de crescimento, forte aumento da desigualdade, o retorno à instabilidade financeira.

O Estado brasileiro acompanhou com atraso essas transformações. Em $A$ Construção Política do Brasil (2014), eu dividi a história do Brasil em três grandes ciclos que marcaram a relação entre a sociedade e o Estado na história independente do Brasil. O primeiro é o da formação do Estado e da integração do território, e cobre o período do Império; denomino-o Ciclo Estado e Integração Territorial. Depois de um período de transição, que é o da Primeira República, temos o segundo ciclo - a Revolução Capitalista Brasileira (ou Ciclo Nação e Desenvolvimento) -, que vai da Revolução de 1930 até os anos 1970 e coincide com a formação do Estado-nação e a revolução industrial brasileira. Finalmente, a partir de 1980, quando já se podia considerar completada a revolução capitalista e o Brasil estava maduro para a democracia, começa o Ciclo Democracia e Justiça Social, que irá terminar com a crise política que se inicia em 2013 e a crise econômica de 2014. Quando esse ciclo estava terminando, eu pensei na possibilidade de que uma síntese pudesse vir a se produzir entre o crescimento econômico do segundo ciclo e a diminuição das desigualdades do segundo, mas a crise foi maior do que esperava, e em 2018, o Brasil continua imerso em grave crise econômica e mais grave ainda crise política.

Os nomes dos três ciclos da relação Estado-sociedade indicam bem a natureza de cada ciclo. Durante o Ciclo Estado e Integração Territorial formou-se o Estado brasileiro-um Estado patrimonialista herdado dos portugueses no qual se confundia o patrimônio público com o patrimônio privado. Não foi, porém, um período 
marcado pela corrupção nem pela captura do Estado, a não ser no que diz respeito aos comerciantes associados ao tráfico de escravos. O Estado era oligárquicopatrimonialista, representando os interesses dos grandes proprietários de terras e da burocracia patrimonialista. Esta estava dirigida por um monarca voltado para o interesse público, e comandava politicamente o país, comprometida com a construção do Estado e a integração territorial. ${ }^{1}$ Mas não era uma elite nacionalista, não estava voltada para a industrialização e não tinha uma atitude crítica em relação ao imperialismo, que, conforme Barbosa Lima Sobrinho (1981) acentuou, é definidora do nacionalismo econômico nos países da periferia do capitalismo. Conforme observou Adrián Gurza Lavalle (2004: p.41), referindo-se ao problema da nação no Império, "a impossibilidade de se admitir a existência do estado-nação como um dado do século XIX foi ponto cego para boa parte do pensamento políticosocial brasileiro". A elite não foi, portanto, capaz de construir um verdadeiro Estadonação soberano. Limitou-se a construí-lo enquanto sistema constitucional-legal e a organização que o garante, e a manter unificado seu território. O problema que o Império enfrentou estava nas oligarquias regionais que resistiam ao processo de estaticidade e nas revoluções independentistas como a Revolução Pernambucana de 1817, a Confederação do Equador de 1824, a Revolução Farroupilha de 1835 a 1845, e movimentos sociais regionais, como Canudos e o Contestado. O Império enfrentou com violência essas ameaças de divisão e manteve a integridade do grande território brasileiro. ${ }^{2}$

Não havia nesse período nem nacionalismo, nem ideia de nação, ou de desenvolvimento. Quando se discute a relação Estado-sociedade, geralmente se supõe que a nação precede o Estado, mas não foi esse o caso do Brasil. Na relação sempre dialética entre sociedade e Estado-nação, foi este que prevaleceu no seu primeiro grande ciclo. O Estado, porém, estava voltado para a ordem pública. 0 desenvolvimento econômico que houve, baseado na cultura do café, não contou com apoio significativo do Estado; foi antes o resultado da iniciativa de uma burguesia agrária que abandonou o trabalho escravo e soube aproveitar a oportunidade que a produção do café a presentava para transitar de um capitalismo mercantil e patriarcal para um capitalismo relativamente moderno, no qual as ideias de produtividade e competição já estavam presentes, ainda que de forma imprecisa.

Com a Revolução Capitalista Brasileira (1930-1980) ocorre uma mudança fundamental. Ao contrário do que aconteceu no ciclo anterior, agora a sociedade e o Estado passaram a formar um todo voltado para um projeto: a industrialização. Enquanto ao nível da sociedade as ideias nacionalistas já estavam avançadas desde

\footnotetext{
${ }^{1}$ Ver o estudo definitivo de José Murilo de Carvalho (1980) sobre a burocracia pública brasileira do Império.

${ }^{2}$ Sobre a estaticidade e a formação do Estado ver Oscar Oszlak (1997, Introdução).
} 
o início do século, foi apenas com a Revolução de 1930 que surgiu a primeiracoalizão de classes voltada para o desenvolvimento econômico. O Pacto Nacional-Popular de 1930 (1930-59) foi um pacto "desenvolvimentista" porque o Estado passou a intervir moderada mas efetivamente na economia; "nacional" porque envolveu a burguesia comprometida com a industrialização; e "popular" porque as classes populares pela primeira vez se constituíram em poder político. Esse pacto teve Getúlio Vargas como seu principal ator político. Ele compreendeu a gravidade da crise mundial iniciada com o crash da bolsa de Nova York em 1929 e a oportunidade que se abria para o Brasil. Assim, rompeu a aliança que fizera com os liberais (que representavam os interesses do café e do comércio externo) e se associou aos nacionalistas que vinham se manifestando cada vez mais ativamente no plano político, principalmente no movimento tenentista. Ao mesmo tempo, como líder político, buscou pela primeira vez na história do país apoio nas massas urbanas. Vargas logrou unir em um pacto informal nacional-desenvolvimentista a burguesia industrial nascente, a burocracia pública moderna que também estava dando seus primeiros passos, a classe trabalhadora urbana, os intelectuais nacionalistas, e setores da velha oligarquia "substituidores de importações" (que não produziam para a exportação), principalmente os criadores de gado do Sul e do Nordeste. Na oposição ficavam a oligarquia agrário-exportadora, as classes médias liberais e os interesses estrangeiros. Nesse período o Brasil realiza sua revolução nacional e industrial, ou seja, sua revolução capitalista. Constrói então um verdadeiro Estadonação, dotado de soberania. O regime foi autoritário como, aliás, foram todos os regimes políticos de todos os países no período em que realizaram suas respectivas revoluções capitalistas. ${ }^{3}$

Entretanto, o desequilíbrio econômico deixado por Kubitscheck e a Revolução Cubana de 1959 provocaram radicalização na esquerda e na direita, e levaram ao golpe militar de 1964. Com ele, os militares, que sempre foram o esteio do nacionalismo brasileiro, atemorizados com a ameaça comunista, associaram-se aos norte-americanos na instauração de um regime militar no Brasil. Forma-se, então, um segundo pacto político - o Pacto Autoritário-Modernizante de 1964 - o qual, ao contrário do que então esperavam os liberais e a esquerda, dará continuidade à estratégia nacional-desenvolvimentista do período anterior. Esse pacto político teve a mesma composição do anterior em termos de elite - burguesia nacional e burocracia pública (na qual os militares haviam se tornado dominantes) -, mas excluía os trabalhadores e os intelectuais de esquerda, enquanto os interesses

\footnotetext{
${ }^{3}$ Ao contrário de crença arraigada, os Estados Unidos não foram exceção nessa matéria. Só alcançaram o sufrágio universal muito depois de realizar, em meados do século 19, sua revolução industrial e, assim, completar sua revolução capitalista.
} 
estrangeiros, que haviam sido importantes no momento do golpe, perderam em seguida boa parte de sua influência. ${ }^{4}$ Não obstante a estratégia nacional de desenvolvimento fosse nacionalista ao dar clara precedência às empresas nacionais sobre as estrangeiras, e embora a política de desenvolvimento econômico estivesse apoiada no Estado e no controle da taxa de câmbio, o regime militar não perdeu o apoio dos países ricos. A intervenção do Estado era algo perfeitamente aceitável naquela época, já que se praticava também no Norte. Além disso, o país continuava aberto aos investimentos das empresas multinacionais e associado aos Estados Unidos na Guerra Fria.

O Pacto Autoritário-Modernizante foi comandado pela tecnoburocracia pública e contou com a participação ativa da burguesia industrial, principalmente da indústria de bens de capital. Enquanto o Estado, diretamente ou através de empresas estatais, investia na infraestrutura e nas indústrias de base, o setor privado nacional investia na indústria de transformação, em muitos casos associada às empresas multinacionais. ${ }^{5}$ Com a grande crise do endividamento externo dos anos 1980 e a alta inflação inercial que dela decorre e da indexação formal da economia adotada pelos militares desde 1964, o regime militar entrou em crise e terminou em 1985, ao completar-se a transição democrática. O Estado brasileiro durante o Ciclo Nação e Desenvolvimento foi um Estado autoritário e desenvolvimentista. A "democracia de 1946-64" não foi realmente uma democracia, já que não dava direito de voto aos analfabetos. No plano administrativo, o Estado se moderniza ao realizar sua Reforma Burocrática, a partir de 1936, e sua Reforma Desenvolvimentista (DecretoLei no 200), a partir de 1968.

No terceiro ciclo da relação Estado-sociedade, Ciclo Democracia e Justiça Social, que começa com os grandes movimentos populares e a luta pela democracia a partir de 1979, o Estado brasileiro será finalmente democrático e buscará reduzir a gravíssima desigualdade social herdada da colonização por exploração mercantil e do longo período escravista. A transição democrática de 1985, efetivada pelo fim do regime militar e pelo estabelecimento do sufrágio universal, abriu um período de grandes esperanças, que foi marcado pela transformação do Estado brasileiro em um Estado social, no qual se garantiram a universalidade do ensino fundamental e a universalidade dos cuidados de saúde; no plano administrativo, teve início a Reforma Gerencial de 1995, cujo principal objetivo foi tornar eficientes os grandes serviços

\footnotetext{
${ }^{4}$ Guilherme O’Donnell (1973) denominou esse pacto Burocrático-Autoritário. Eu sempre o denominei AutoritárioModernizante. Na 5ạ edição de Desenvolvimento e Crise no Brasil (2003), resolvi usar a expressão de O'Donnell, mas decidi mais tarde voltar à expressão original que reflete melhor o caráter modernizador desse pacto.

${ }^{5}$ Estudando a indústria petroquímica, Peter Evans (1979) fez a análise da "tríplice aliança" envolvendo o Estado, o capital nacional e o capital estrangeiro, que, no caso da indústria petroquímica, foi uma aliança formal prevista na política do Estado.
} 
sociais do Estado e legitimar o aumento da carga tributária necessário para financiar esses serviços. Esse ciclo nasceu da reação das forças populares e dos intelectuais de esquerda ao golpe de 1964, e foi ganhando força na medida que os intelectuais afiavam sua crítica ao regime militar, não só por seu autoritarismo mas também pelo aumento da desigualdade, e em que novos setores sociais iam se associando à luta pela democracia e pela diminuição das desigualdades. ${ }^{6}$ Primeiro, ocorreu a adesão dos movimentos católicos liderados pelo cardeal de São Paulo, dom Paulo Evaristo Arns, que se revelou um destemido crítico das violências contra os direitos humanos que então se praticavam. O novo ciclo ganhou impulso no plano político em 1977, com o início da crise do regime autoritário. A crise se desencadeia como uma reação ao "Pacote de Abril" de 1977, um conjunto de medidas violentamente autoritárias que o Presidente Ernesto Geisel adota nesse mês, depois de, nos dois anos anteriores, ter anunciado que estava iniciando a "distensão" ou a "abertura" democrática. As medidas autoritárias foram recebidas de forma negativa pela burguesia, e, a partir de então, esta, pela primeira vez desde 1964, deixa de dar amplo apoio ao governo, e, gradualmente, se associa às forças democráticas. Com esse fato histórico novo iniciava-se a transição democrática no Brasil; começou então a se formar o Pacto Democrático-Popular de 1977, um pacto abrangente que foi impulsionado pela crise econômica que começou em 1980 (a grande crise da dívida externa e da alta inflação inercial), e foi vitorioso alcançando a democracia no final de 1984, depois de ampla mobilização popular - a campanha das Diretas-Já. No entanto, apenas dois anos depois, no início de 1987, o novo regime democrático enfrentou grave crise econômica e política na medida em que o Plano Cruzado, de 1986, que havia zerado a alta inflação inercial herdada do regime militar, no fim desse ano, entrou em colapso e a inflação voltou com toda força, o que gerou uma forte decepção popular em relação aos políticos que haviam comandado a transição democrática. ${ }^{7}$ O momento maior do Ciclo Democracia e Justiça Social foi a promulgação da Constituição de 1988 - uma constituição democrática, social e participativa, que foi recebida com frieza pelas elites conservadoras do país, que a consideraram "utópica" e "inviável". Não obstante, sua mais significativa determinação - a do estabelecimento de um sistema universal de saúde - tornouse realidade com o SUS - o Sistema Único de Saúde. Ao começar, em meados dos anos 1970, esse ciclo estava diante de um país em que a desigualdade era imensa;

\footnotetext{
${ }^{6}$ Fiz a primeira análise publicada do novo modelo de crescimento com concentração de renda da classe média para cima (BRESSER-PEREIRA, 1970) a partir de uma conferência de Antonio Barros de Castro. Seguiu-se o texto bem conhecido de Tavares e Serra (1971).

${ }^{7}$ Só o fracasso do Plano Cruzado pode explicar a derrota de líderes políticos da dimensão de Ulysses Guimarães, Mário Covas, Leonel Brizola e Luiz Inácio Lula da Silva perante um jovem e desconhecido político, Fernando Collor de Mello.
} 
trinta anos depois, não obstante o neoliberalismo que atingiu o mundo e se refletiu no Brasil, estava instalado no país um Estado do bem-estar social, e a desigualdade, embora continuando elevada, havia diminuído sensivelmente. ${ }^{8}$

O Ciclo Democracia e Justiça Social cumpriu suas promessas, porque logrou implantar afinal a democracia no Brasil e porque alcançou alguns resultados na luta pela igualdade econômica e de gênero. Mas não logrou levar o país a retomar o desenvolvimento econômico. Os líderes democráticos encontraram o país em meio a grave crise econômica caracterizada por uma grande crise financeira e pela alta inflação inercial. Nos 30 anos seguintes esses problemas imediatos foram superados, mas outros surgiram. Em 1990, curvando-se à virada em direção ao neoliberalismo ocorrida nos países ricos em 1980, o Brasil se curvou ao Consenso de Washington, e adotou um regime de política econômica liberal. Caiu, então, em uma armadilha macroeconômica de juros altos e câmbio apreciado no longo prazo, que inviabilizaram o investimento na indústria, causaram forte desindustrialização, e condenaram a economia brasileira a crescer a menos de um por cento per capita a partir de 1980 , enquanto, no ciclo anterior, crescia a 4,5 por cento per capita. Em 2013, grandes manifestações populares, indicam o início de uma crise política, que se agravou quando, em 2014, o país entrou em grave recessão. Encerrou-se, assim, o Ciclo Democracia e Justiça Social.

\section{Captura}

A quase-estagnação da economia brasileira desde 1980 tem muitas explicações. Uma delas é a existência de grupos de interesse poderosos que desrespeitam de maneira sistemática os direitos republicanos dos cidadãos brasileiros, desta prática resultando privilégios legais, elevado índice de desigualdade econômica, altas taxas de juro, câmbio apreciado no longo prazo e baixa taxa de investimento. Digo privilégios "legais" porque os privatizadores do patrimônio público não agem de forma corrupta, mas de acordo com a lei. A corrupção é também uma causa de privatização do Estado, mas é uma forma que está definida pela lei como crime. A violência aos direitos republicanos que nos interessa é aquela que ainda continua acobertada pela lei e, portanto, pelo próprio Estado.

No Brasil, hoje, um primeiro grupo de interesses que captura o patrimônio público brasileiro é o dos capitalistas rentistas e dos financistas. O capitalismo neoliberal é um capitalismo financeiro-rentista. Isso vale para os países ricos

\footnotetext{
${ }^{8}$ Gastando cerca de 1/4 do PIB com despesas sociais de educação, saúde, cultura, previdência social e assistência social, o Brasil hoje, por esse parâmetro, se aproxima dos países europeus definidos como Estados do bem-estar social.
} 
e vale também para o Brasil. Os empresários capitalistas, desde a virada para o século 20, foram substituídos na gestão das empresas pelos tecnoburocratas, e, a partir da Segunda Guerra Mundial, foram substituídos na propriedade das empresas pelos rentistas, ou seja, por seus herdeiros e por especuladores, que se associaram aos tecnoburocratas financistas, que administram a riqueza dos rentistas e servem como seus intelectuais orgânicos usando a teoria econômica neoclássica para legitimar o liberalismo econômico radical. No Brasil, embora essas duas substituições estejam menos avançadas, os rentistas e financistas alcançaram um poder surpreendentemente alto, para o qual contribuiu, de um lado, o fracasso dos governos desenvolvimentistas, primeiro, no governo José Sarney (1995-1999), e, segundo, no governo Dilma Rousseff (2011-2016), e, de outro, a dependência das elites brasileiras, inclusive a alta classe média, em relação às ideias dominantes nos Estados Unidos. Os juros reais que rentistas e financistas recebem do Estado, ainda que venham caindo desde 1994, quando foram estabelecidos em níveis estratosféricos para combater a inflação e atrair capitais, continuam altíssimos e, além de serem uma causa básica da apreciação cambial de longo prazo que vem inviabilizando a indústria brasileira, são um mecanismo de apropriação do patrimônio público poderoso.

Um segundo grupo são os ricos, que estão isentos de impostos sobre dividendos, que praticamente nada pagam nas heranças, e que se beneficiam de um sistema tributário dotado de baixíssima progressividade no qual os pobres pagam, proporcionalmente a seus rendimentos, muito mais. Seria preciso também considerar os que sonegam impostos, mas a sonegação é uma violência aos direitos republicanos bem identificada e já proibida pela lei.

Um terceiro grupo importante de capturadores do patrimônio público são os altos servidores e membros do governo que recebem remunerações muito maiores do que o valor do seu trabalho. Na emenda 19 da Reforma Gerencial do Estado de 1995 foi estabelecido um teto para essa remuneração que vale para todos os tipos de benefício que se possa imaginar, mas os tribunais não respeitam a determinação constitucional. Esses altos servidores são também especialistas em mover ações contra o Estado para receber vantagens dos mais variados tipos.

Um quarto grupo são os dirigentes de igrejas e de outras entidades sem fins lucrativos, que recebem isenções fiscais descabidas.

Um quinto tipo são os empresários que recebem subsídios dos mais variados tipos, que uma competente política industrial não justifica, porque não estimulam o investimento, apenas enriquecendo seus beneficiários.

Um sexto grupo é o das empresas que vendem serviços e bens, ou obtêm concessões públicas e participam de parcerias público-privadas, nos dois casos 
por preços superiores ao que vale o serviço ou o bem. Observe-se que não estou falando de corrupção: estou me referindo apenas à prática de preços abusivos sem propinas e formação de cartéis. Adicionalmente existe o problema bem conhecido das empresas que corrompem servidores para lograrem que seus preços sejam aceitos pelo Estado, ou de servidores que chantageiam empresas, condicionando a dispensa de pagamentos de tributos e de outras obrigações ao recebimento de propina.

Um sétimo grupo é o dos políticos que adotam políticas populistas fiscais ou então cambiais para lograrem se reeleger. Configura-se o populismo fiscal quando o político aumenta de maneira irresponsável as despesas do Estado em benefício de determinados grupos ou "para aumentar a demanda agregada". É claro que, nos momentos de desemprego, uma política fiscal contracíclica é amplamente justificável, mas querer resolver todos os problemas econômicos através do aumento da despesa pública, além de constituir uma irracionalidade, é uma apropriação do patrimônio público em benefício do político que procura se reeleger. Configura-se o populismo cambial quando o Estado estimula déficits em conta-corrente e eleva os juros para atrair capitais externos que apreciam no longo prazo a moeda nacional e tornam as empresas industriais do país, sejam elas nacionais ou multinacionais, não-competitivas, sem condições para investir. ${ }^{9}$

Por fim, um oitavo e enormemente importante grupo, o dos capturadores de um patrimônio público fundamental de qualquer sociedade, o meio-ambiente ou a natureza. Hoje nós sabemos quão precioso é esse patrimônio para a sobrevivência da humanidade, e quão ameaçado ele está.

\section{Conclusão}

Cada uma dessas formas de captura do patrimônio público merece análise mais profunda e sua quantificação, mas essa é uma tarefa que escapa aos objetivos deste breve trabalho. Vale, porém, observar que, em todos esses casos, vemos um Estado vulnerável sendo capturado ou privatizado por grupos de cidadãos poderosos. Temos assim o caso oposto e complementar ao dos direitos civis. Enquanto estes pressupunham cidadãos indefesos e um Estado absoluto poderoso, aqui vemos o inverso.

Quando iniciei a Reforma Gerencial de 1995, eu tinha como principal objetivo tornar mais eficientes os grandes serviços do Estado social, não apenas porque um razoável nível de eficiência no serviço público é um objetivo em si mesmo, mas, mais especificamente, para garantir legitimidade (apoio na sociedade) aos impostos

9 Sobre o populismo fiscal e cambial ver Bresser-Pereira, Oreiro e Marconi (2016). 
que devem financiá-los. Os serviços universais de educação, saúde, previdência básica e de polícia são uma forma de diminuir a desigualdade e dar segurança à população. São direitos sociais que ganham apoio na sociedade se estiver claro para ela que os impostos correspondentes estão sendo bem usados, em vez de beneficiarem empresários corruptos e servidores incompetentes. Enquanto os direitos civis pressupõem cidadãos fracos perante um Estado todo poderoso, os direitos republicanos pressupõem cidadãos e grupos poderosos que buscam capturar um Estado vulnerável. Isso estava claro para mim quando, em novembro de 1996, proferi uma primeira conferência conceituando os direitos republicanos na Faculdade de Direito da Universidade de São Paulo. O notável administrativista Celso Antônio Bandeira de Mello leu o artigo e me disse então: "Agora compreendo melhor a reforma; os direitos republicanos estão na sua base". Eu creio que ele tem razão. O Brasil precisa de um Estado forte ou capaz - um Estado republicano que seja o grande instrumento de ação coletiva da sociedade brasileira. A Reforma Gerencial visou ajudar a construir um Estado republicano, capaz de se defender das tentativas de captura, e um Estado do bem-estar social que diminua as desigualdades inerentes ao capitalismo.

Como tornar o Estado republicano? Essencialmente, tornando-o mais democrático, ou seja, reduzindo o poder dos privatizadores do Estado - o poder dos rentistas que recebem juros absurdamente altos do Estado; o poder da alta burocracia pública que recebe salários e aposentadorias elevados demais; o poder das empresas que recebem subsídios que se supõe refletirem equivocadamente uma política industrial estimuladora do investimento; o poder das organizações sem fins lucrativos que, na verdade, agem como empresas em benefício de seus dirigentes. Não seria, também, reduzindo a corrupção? Sem dúvida, para isso não é necessário invocar os direitos republicanos, já que a corrupção é um crime devidamente previsto no direito penal. Os direitos republicanos são um conceito importante, porque os capturadores do patrimônio público o capturam legalmente - amparados pela lei ou pela jurisprudência. A garantia dos direitos republicanos supõe, portanto, um aperfeiçoamento das instituições que proíbam e criminalizem a captura privada do Estado por grupos de interesse. Enquanto o remédio para a corrupção é sua denúncia e punição, o remédio para os demais direitos republicanos é identificar a violência contra eles também como crimes e puni-los. 


\section{Referências}

BARBosA Lima Sobrinho, Alexandre. Estudos nacionalistas. Rio de Janeiro: Editora Civilização Brasileira, 1981.

BRESSER-PEREIRA, Luiz Carlos (1970 [1972]) Dividir ou multiplicar? A distribuição da renda e a recuperação da economia brasileira. Visão, 21 de novembro 1970. Republicado em Bresser-Pereira, Desenvolvimento e Crise no Brasil, desde sua terceira edição, 1972.

BResser-PereIRA, Luiz Carlos Cidadania e res publica: a emergência dos direitos republicanos. Revista de Filosofia Política - Nova Série, v.1, p. 99-144 (Porto Alegre: Universidade Federal do Rio Grande do Sul, Departamento de Filosofia), 1997.

BRESSER-PEREIRA, Luiz Carlos (1968/2003) Desenvolvimento e Crise no Brasil, 5a edição, São Paulo: Editora 34, 2003. Primeira edição, Rio de Janeiro: Zahar Editores, 1968.

Bresser-Pereira, Luiz Carlos (2004 [2009]) Construindo o Estado Republicano. Rio de Janeiro: Editora da Fundação Getúlio Vargas, 2004. Original em inglês.

BRESSER-PEREIRA, Luiz Carlos (2014 [2016]) A construção política do Brasil. 3. ed. São Paulo: Editora 34, 2016.

Bresser-PereIRA, Luiz Carlos; OreIRo, José Luis; MARConi, Nelson. Macroeconomia desenvolvimentista. Rio de Janeiro: Elsevier, 2016.

CARVAlho, José Murilo de A construção da ordem. Brasília: Editora Universidade de Brasília, 1980.

Evans, Peter. Dependent development: the alliance of multinational, local and State capital in Brazil. Princeton: Princeton University Press, 1979.

LAVALLE, Adrián Gurza. Vida pública e identidade nacional: leituras brasileiras. Rio de Janeiro: Editora Globo, 2004.

MARSHALL, T.H. (1950 [1992]) Citizenship and social class. In: MARSHALL, T. H.; Bottomore, Tom. Citizenship and social class. London: Pluto Press, 1992. Originalmente publicado em 1950. p. 1-51.

O'DONNELL, Guillermo. Modernization and bureaucratic authoritarianism: studies in South American politics. Berkeley: Institute of International Studies of the University of California, Berkeley, Modernization Series 9, 1973.

OSZLAK, Oscar. Estado e sociedade: novas regras do jogo. In: DINES, Alberto et al. Sociedade e Estado: superando fronteiras. São Paulo: Edições Fundap, 1998 p. 47-110.

TAVAres, Maria da Conceição; SerRA, José (1971[1972]) Além da estagnação. In: TAVARES, Maria da Conceição. Da substituição de importações ao capitalismo financeiro. Rio de Janeiro: Editora Zahar, 1972. Edição original em espanhol, 1971. 
RSP 